\title{
Application Scales, Dimensions and Scenarios of City Information Modeling (CIM) -Based on the Practice in Guangzhou, China
}

\author{
Yankai WANG, School of Architecture, South China University of Technology, China \\ Miaoxi ZHAO, School of Architecture, South China University of Technology, China \\ Shunqing CHEN, Augur Intelligence Technology (Guangzhou) Co., Ltd, China \\ Qizhi CHEN, Augur Intelligence Technology (Guangzhou) Co., Ltd, China
}

\begin{abstract}
City Information Modeling (CIM), on the basis of Building Information Modeling (BIM), Geographic Information System (GIS), Internet of Things (IOT) etc., has incorporated a full-factor spatial model with two and three-dimensional information and data of cities, and therefore, is a fundamental and critical platform for smart city construction. Based on CIM platform, simulation of scheme for city planning and design has brought it to fruition in the following aspects: it can carry out simulation in a world of digital twin to discover experiences and laws, moreover, it can effectively be implemented and executed in this physical world so as to cut costs in terms of trialand-error; and a benign interaction of "virtual vs. real" nature is therefore achieved. From this perspective, the construction and application of CIM platform are of great practical significance to improve the comprehensive city management and operation capability. This research, based on the clarified construction principle and development of CIM, combining with the practice in Guangzhou city, has elaborated the specific application of CIM platform in different spatial scale, such as monomer construction, communities (campus) and cities, and also application at different operating stage, including city planning, design, construction, management and operation. Moreover, this research takes the representative application scenarios of "CIM+Smart Site", "CIM + smart parking" and "CIM + city renewal" into account, based on which, analyses the chief role and its function as guiding framework concerning CIM platform in city management. Stemmed from these efforts, practical experience is therefore summarized, providing reference to further explore extensive "CIM +" application and promote the construction of city information digital platform for related sectors.
\end{abstract}

\section{Keywords}

City information Modeling (CIM) platform,Application scales, Application dimension, Application scenarios, Guangzhou city

\section{Introduction}

City Information Modelling (hereinafter referred to as $\mathrm{CIM}$ ), on the basis of Building Information Modelling (BIM), Geographic Information System (GIS), Internet of Things (IOT) and other technologies, integrates multi-dimensional and multi-scale information model data and urban perception data, including the dimensions of over ground and underground, indoor and outdoor, the past, present and future, etc. so as to build a three-dimensional digital space for city information organic 
complex(Xu,2014;Wang,2021). Under the framework of this CIM, 3DGIS can help realize the digital simulation and spatial analysis on the city macroscopic scenes; while BIM can accurately showcase the physical facilities and functional information of the city's cell-like (over ground and underground) buildings; moreover, loT functions as the neuronal network that penetrates into the city macroscopic scenes, and the interior and exterior of the cell-like buildings. By and large, CIM furnishes new avenues toward data fusion, method integration and function integration for different information technologies, provides support on the information level for urban management applications at different scales and in different scenarios. Such efforts are conducive to laying solid foundation for the transformation and upgrading of urban management, and to the orientation of refinement, informatization and intelligence.

$\mathrm{CIM}$, as its great application and development potential in the domain of urban construction and management, has been attached great significant by the Chinese government and pertinent industries. In 2018, the Ministry of Housing and Urban-Rural Development (MOHURD) of China set forth the guideline of constructing a CIM platform based on the application of BIM technology. Beijing, Guangzhou, Nanjing, Xiamen and Xiong'an New Area were list as pilot cities for its application. On the strength of BIM, CIM technology mainly aims to accomplish the manifold tasks, such as reviewing and approving engineering construction projects in electronic form, exploring the construction of CIM platform, unifying technical standards, strengthening system construction, and satisfying the requirement of "China Smart 2035". Such endeavours will be conducive to realizing electronic review and approval of the whole life cycle of engineering construction project, promoting the integration of planning, design, construction, management and operation of the whole cycle of engineering construction projects; besides, it can also constantly enrich and enhance urban planning/construction management data information, laying a solid foundation for the construction of a smart city management platform. In addition to the five pilot cities announced by the Ministry of Housing and Urban-Rural Development, Shanghai Yangpu Binjiang Area, Guangzhou Nansha Pearl Bay, Qingdao Central Business District, Shaanxi Xi'an New Area, etc. are all working on the implementation of CIM platform and applications to varying degrees. Among them, Guangzhou, as a typical mega-city in China, its CIM platform has already covered the whole city, reaching $7434.4 \mathrm{~km}^{2}$, which has shed light on the CIM implementation campaign.

In August 2019, following the consent of the Guangzhou Municipal Government and putting in file in the Ministry of Housing and Urban-Rural Development, Guangzhou City issued the Guangzhou City Information Model (CIM) Platform Construction Pilot Working Plan. The Plan established a pilot work for joint meeting system with the mayor as the general convener and the vice mayor as the executive convener in charge of urban construction work, while the working mechanism was led by the Municipal Housing and Urban-Rural Development Bureau, with the Planning and Natural Resources Bureau, the Government Services and Data The city's 21 municipal departments and large state-owned enterprises coordinate jointly to promote the mechanism. Based on the CIM platform, Guangzhou has realized light data model, accession management and fast loading display, and has developed simulation and analysis functions such as visibility analysis, bridge inspection, traffic simulation and flooding simulation etc. (Li, 2014). The CIM platform has furnished a connection channel for commercialized applications in many fields such as transportation, water, industry, landscaping, industry, epidemic prevention and control, etc., and promoted the construction of a diversified CIM application system. In summary, Guangzhou city took the pilot program as an opportunity to vigorously carry out commercialized application exploration centred on the enhancement of urban governance intelligence and to further integrate each sectors; on the strength of integrating various subsystems such as housing and construction project management platform and industry management platform, a unified management platform therefore was therefore available. Besides, a CIM platform operation command centre will be a priority of next working stage(Shi,2020), based on which, CIM technology in $\mathrm{CIM}+$ real estate market monitoring, $\mathrm{CIM}+$ urban renewal, $\mathrm{CIM}+$ old community transformation, $\mathrm{CIM}+$ city physical examination, $\mathrm{CIM}+$ beautiful 
countryside, $\mathrm{CIM}+$ epidemic prevention and control, $\mathrm{CIM}+$ forestry garden, $\mathrm{CIM}+$ smart site, $\mathrm{CIM}+$ smart water, $\mathrm{CIM}+$ smart community, $\mathrm{CIM}+$ smart park and $\mathrm{CIM}+$ industrial informationization will be expanded in its scale. Such efforts will boost related industries to improve their basic capabilities and promote the integration of informationization and urbanization in a wider scope, more in-depth degree and higher level.

\section{The necessity and feasibility of CIM construction}

\subsection{Necessity}

In March 2020, Chinese President Xi Jinping pointed out during his visit to Zhejiang Province that "we should use cutting-edge technologies like big data, cloud computing, block chain, artificial intelligence etc., to promote innovation in urban management methods, modes and philosophy, so that cities can evolve from digitalization to intelligence to a smart ones. This is the path leading to a modern urban governance system and governance capacity. With the improvement of China's urbanization, the scale of cities is getting bigger and bigger, traffic congestion, environmental pollution and housing safety and other urban problems are becoming more and more prominent. Against such backdrop, the traditional urban management and operation and maintenance model can no longer support the future needs of the city, that is to say, seeking more advanced management methods to promote urban construction has become the urgent needs. And therefore, the new generation of information technology to enable the construction of smart cities and the use of data-driven urban governance innovation have become a new trend in the domain. The information projects smart city construction such as the "city brain", "city cloud brain", "leadership cockpit" etc., are emerging everywhere.

All time along, the traditional smart city construction has manifolds problems such as the lack of basic data information, poor information sharing, data silos, and duplicated platform construction etc., which result the failure of integrating data from various aspects of urban planning, construction, and management, and the inability to collaborate and link business. In this context, the notion of City Information Model (CIM) was given birth, bringing new ideas for the construction of new smart cities.

\subsection{Feasibility}

While at the policy level, in December 2017, General Secretary Xi Jinping put forward the general requirement of "accelerating the improvement of digital infrastructure and the construction of a digital China"; in 2019, several cities, including Guangzhou, were approved by the Ministry of Housing and Construction as the first batch of pilot cities for the construction of CIM platform; in 2021, the construction of CIM platform was incorporated into the national 14th Five-Year Plan and the strategic deployment of new city construction. In addition, a series of documents issued by the Ministry of Housing and Construction, such as Guidance on Accelerating the Construction of New Urban Infrastructure and Guidance on the Construction of City Information Model (CIM) Infrastructure Platform, have highlighted the construction of CIM platform, within the framework of which to explore an intelligent road for reform and lay the foundation for the construction of new smart cities. The promulgation of the series of policies becomes strong guarantee for the development of CIM, creating a good development environment for the in-depth application of CIM technology and accelerating its development process.

With respect to the technical level, the fast proceeding of the fourth generation of information technology based on the Internet of Things and information networks also provide strong technical support for the construction of smart cities and CIM applications. On the other hand, it is those technical means and measures that render the construction of CIM platform clear and feasible progressively. 


\section{Application scale of CIM}

After converging various data, the CIM platform then combines algorithms, models and artificial intelligence to realize simulation from building monolith, community to city level, which is ready to support typical scenario applications such as urban design, green building, smart community, smart pipe network and city physical examination. To name a few typical examples, it can simulate the occurrence of rainfall in a city, according to the rainfall intensity and topography, and various sensors installed on rivers and pipeline roads, the scope affected by different inundation depths of a specific area can be simulated and analysed. And thus, it can help flood prevention and warning and provide decision support.

\subsection{Architectural Monoliths}

Guangzhou City Information Model platform as a matter of fact, provides assisted-intelligent review for the "four stages", i.e., planning, design, construction and management of engineering construction projects in Guangzhou, achieving the transformation from manual approval to machine-assisted approval. Meanwhile, the assisted systems of the "four stages" can share the BIM model of the whole process for the CIM platform, contributing CIM data "self-growth".

In the project land planning approval stage, the BIM model (control box) is expected to pushed to the CIM platform through the "multi-planning" management platform. On the strength of the developed intelligent approval tools, 12 planning indicators such as floor area ratio and building density are automatically solicited, while the "planning conditions" are entailed by computer-aided means. In this way, the CIM platform can achieve computer-aided compliance review, reducing man-made errors and review time.

While in the approval stage for architectural design plan review and construction, a specifically developed intelligent approval tools can intelligently review the BIM model of the proposed construction. Following the approval of construction design plan, the BIM model of the architectural design is forwarded to the CIM platform. Such procedure has promoted a few key operations, including the electronic submission and approval, and the self-examination of design for the whole chain, one-click collection of architecture planning indicators, automat filling data in the form, and review of indicators. The endeavours have achieved the categorized management of construction projects, implementation of the mechanism "system review + information commitment system" for small and medium-sized buildings and industrial buildings in the industrial zone etc., reducing the third-party technical review and improving efficiency thereby.

As to the construction approval stage. It necessitates developing a three-dimensional (BIM) assisted electronic review system and forwarding the construction drawing BIM model to the CIM platform. The screening, disassembly and computer language translation of the construction BIM model as per the national architecture, structure, water, heating, electricity and other specialties, as well as fire, human defence, energy saving etc., has achieved the computer-aided review of 247 national code and standard provisions, and made automatic generation of review reports available. Based on the CIM platform, industry managers can digitally and dynamically supervise construction projects from design drawing review, to quality, safety, green construction, progress, etc.

Concerning the completion acceptance stage, construction quality/safety management system and completion acceptance digital filing system are employed to realize assisted acceptance by comparing the BIM completion model. After the acceptance test is qualified, forward the BIM completion acceptance model to CIM platform. The purpose of this operation is to promote 3D construction model and engineering quality acceptance, mapping acceptance, fire inspection, human defence acceptance etc., and to assist in 3D digital completion acceptance filing. 


\subsection{On community (park) scale}

Given the capabilities of CIM fundamental platform in building smart community, Guangzhou Saneyangjing (old neighbourhood), Ruidong Garden (subsidized housing) and Phoenix City Fenghuanyuan (real estate project) were listed as pilot demonstration communities, the operation of CIM platform has realized the integration of housing information, IOT sensor equipment data access, equipment monitoring and early warning, community service management and other functions. And thereby the situation in the community can be monitored 24 hours through IOT equipment to effectively guarantee the safety condition in the community. At the same time, those service facilities around the community are connected to other facilities, achieving the online and offline scene integration and providing convenience and protection for the daily life of residents (Fig.1).

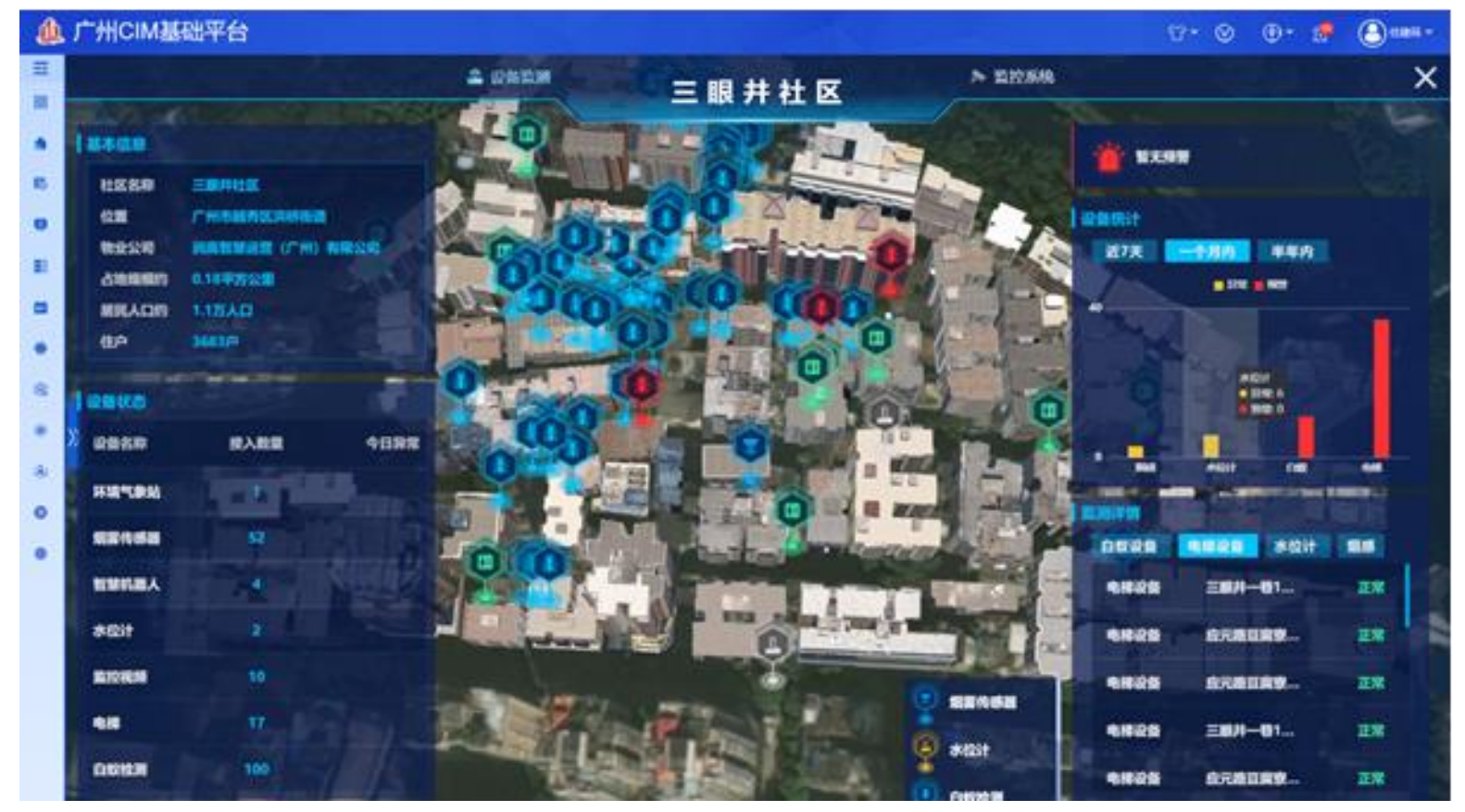

Figure 1. Application in smart community. Source: Augur Intelligence Technology (Guangzhou) Co., Ltd

In terms of the level of smart park or park, CIM technology can be specifically implemented in the planning, construction and operation of the park to coordinate the overall and systematic application of the park. Through information technology, the CIM application helps to innovate community management and promotes the standardization, refinement and scientificization of street work; at the same time, it innovates the service mode and provides residents, neighbourhood and social organizations in the district with humanistic, diversified and socialized public services, so that they may experience of the new intelligent life and enjoy a "fully responsive" intelligent state, which will genuinely improves the operational efficiency and service level.

Under the scale of smart park, CIM technology is specifically landed into the park planning and construction, and coordinates the application of the overall comprehensive system of the park. The smart park application based on the CIM platform contributes to the alignment of the IOT sensing equipment in the park, effectively enhances the overhaul efficiency of the equipment in the park such as fire-fighting, water supply and drainage equipment; meanwhile, it can significantly shorten the processing time of early warning events, efficiently monitors the use of energy consumption on the park, and provides intelligent management means for the operation of the park. Through the CIM platform, the data of various sectors are constantly summarized to provide reference for analysing the orientation of industrial 
development of the park. In other words, the application of CIM in this scenario can provide technical guarantee for improving park management, and propose substantial solutions for optimizing investment appealing, thus continuously improving the image of the park and promoting its high-quality intelligent.

The park bears a variety of complicated sectors and operations(Fig.2), such as catering, enterprises and accommodation, etc. To meet those demands, the application of CIM in this scenario can divide the park parcels and buildings into different layers, plan reasonably as well as display the layout. On the other hand, based on the CIM platform, the distribution and operation of each same sector are statistically calculated, and data from various aspects such as the flow in and out of the park, enterprise distribution and energy consumption are collected to carry out big data analysis and assist in decision-making.

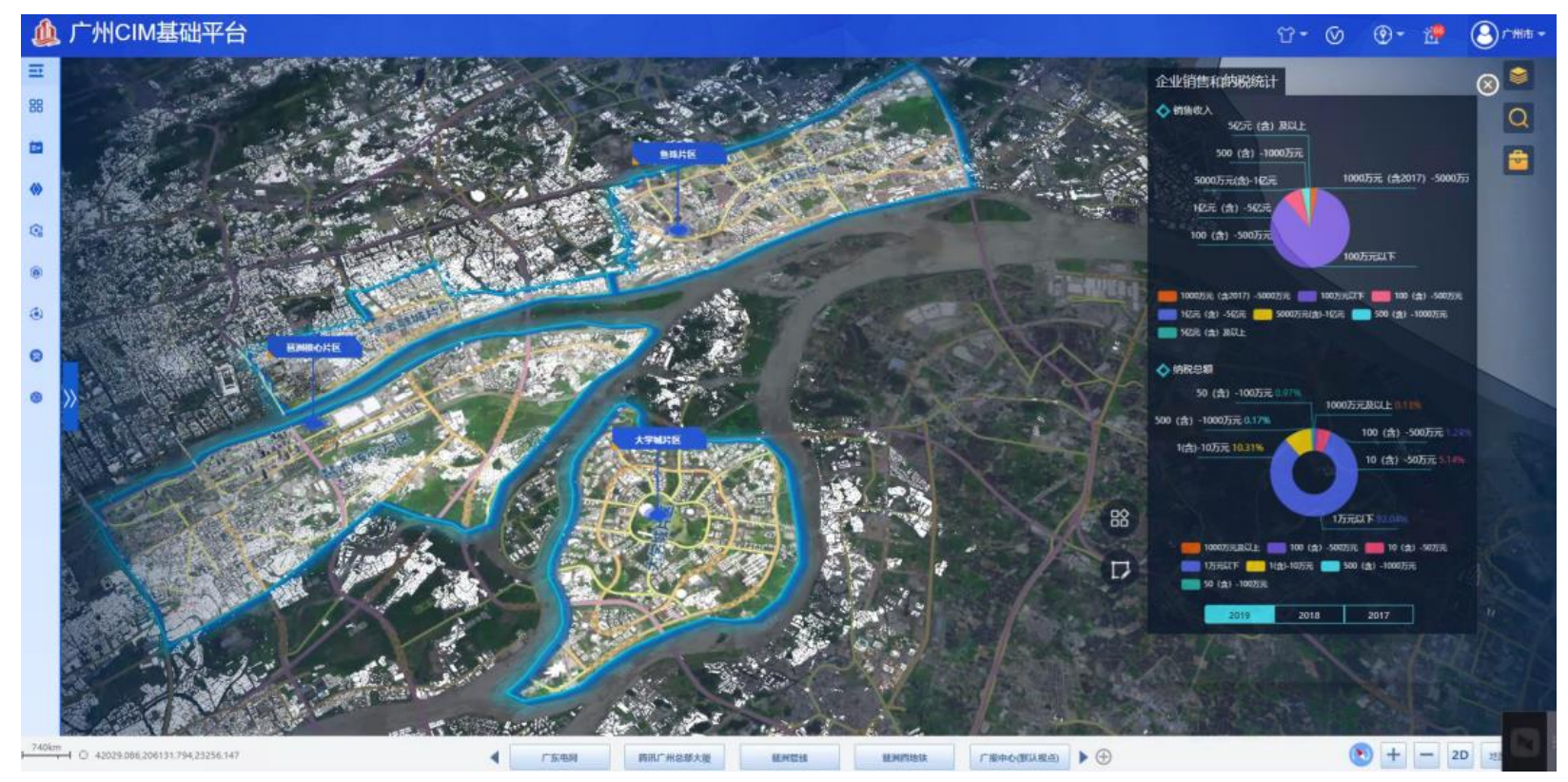

Figure 2. Industry analysis of smart park. Source: Augur Intelligence Technology (Guangzhou) Co., Ltd

In addition, the application scenario of CIM technology in park is able to showcase the complete distribution of buildings, roads, above ground and underground pipeline networks on the park, and realize the classification and multi-level management from the exterior of the building to the internal structure of the rooms based on the model information. Via counting the type and number of people in the park, the type and number of enterprises, the number and area of buildings and other data, the holistic information of the park can be fully learned(Fig.3). 


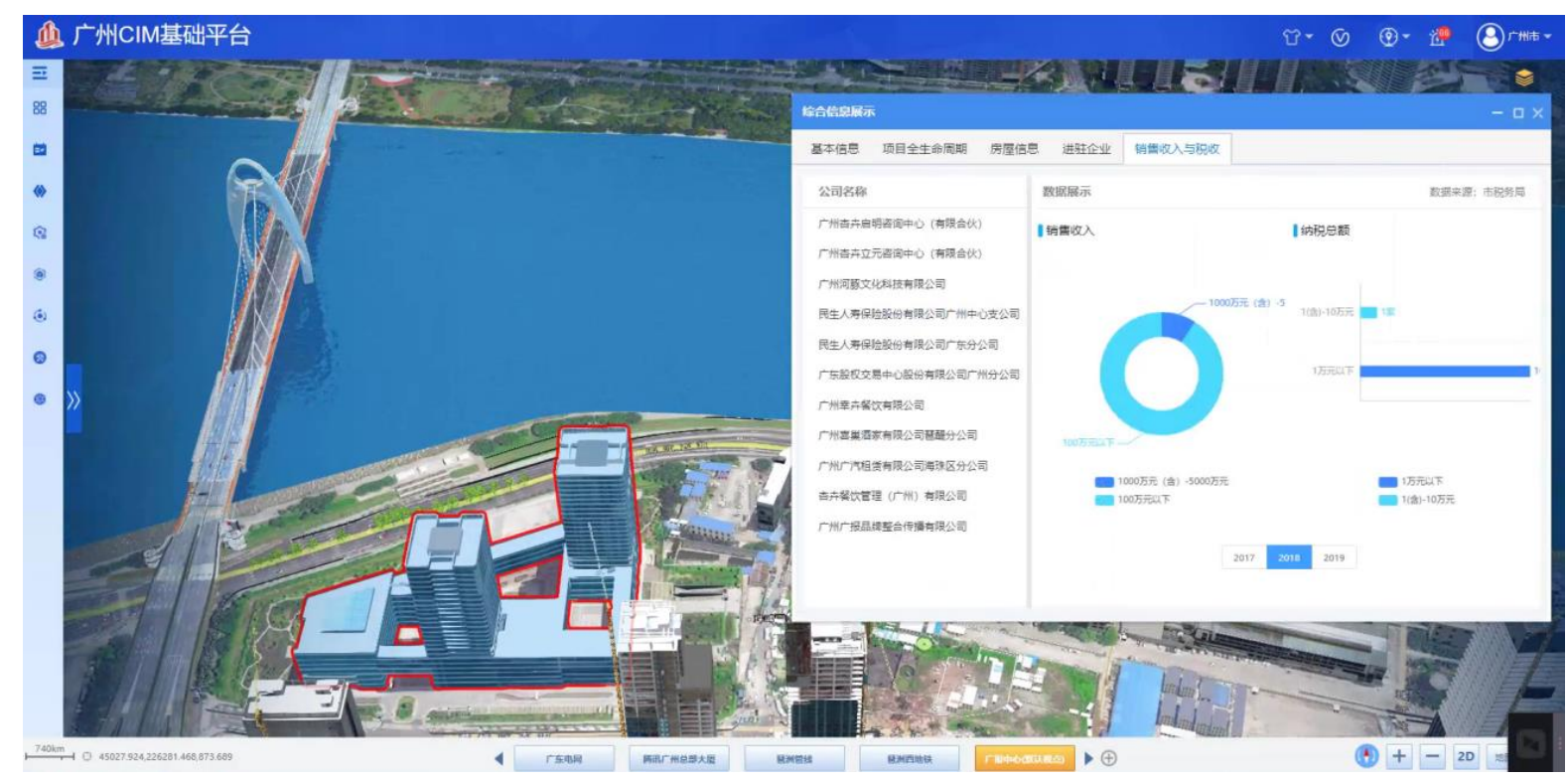

Figure 3. The application interface of the smart park. Source: Augur Intelligence Technology (Guangzhou) Co., Ltd

\subsection{City Scale}

Regarding the city scale, Guangzhou is currently accelerating the construction of a digital government, on the basis of the CIM fundamental platform to build city operation management hub featuring "a network of unified management, the unified management of the whole city". With the application, it is conducive to achieving urban construction, urban management, traffic operations, intelligent water and other 20 targets(Fig.4).

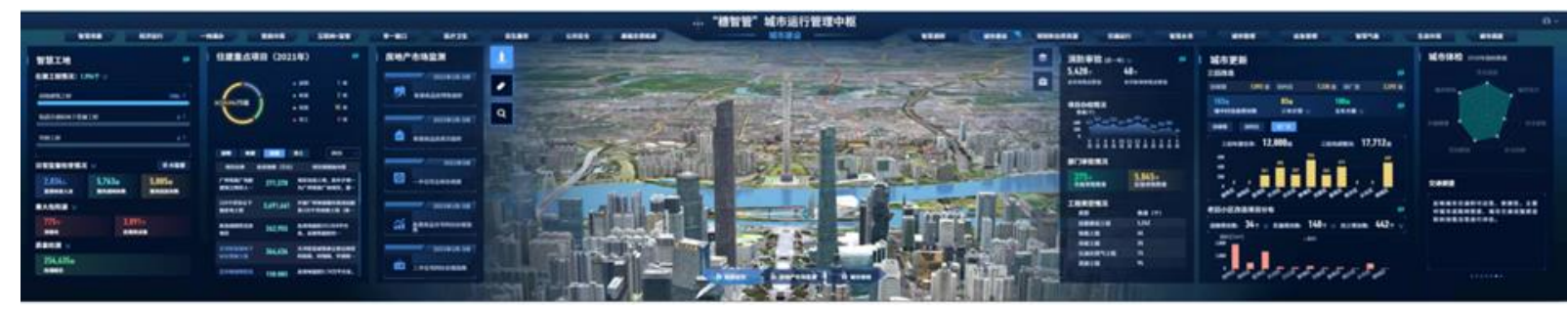

Figure 4. "Sui Smart Management" city operation management hub interface. Source: Augur Intelligence Technology (Guangzhou) Co., Ltd

The "Sui Smart Management" application, taking "intelligence + " as the focus, connects the community end, weaves a dense data grid, dispatches multiple participants, etc., so that it may build a city operation management hub integrating a five-in-one operation monitoring, prediction and early warning, collaborative linkage, decision support, and coordination and dispatch. The effort scan fully support the intelligent and refined urban operation management, comprehensively promote urban governance capacity and modernization of the governance system, and its urban quality development. The main applications include:

\section{(1) Operation monitoring}

By constructing "one drawing" for urban operation monitoring, the urban operation status at multiple levels and in all aspects can be learned in a straightforward manner. Then it should establish a comprehensive urban operation sign and key operation sign index with information centralized and resources integrated, so that it can prevent potential issues from happening. 
(2) Prediction and early warning

It necessitates accessing real-time monitoring data from various departments, establishing correlation analysis of alert information, so as to realize prediction and early warning on operation status of key areas in term of urban transportation, infrastructure, public safety, ecological environment, and social economy. According to the early warning model, the risk level of alarms can be identified, by the means of evaluating the greater risks or possible dangers underneath the current alarm information, based on which, it should activate the corresponding emergency plans as per the different risk levels. In this way, the CIM platform can help realize the transformation of urban operation management from passive response to real-time monitoring, rapid warning and active prevention.

(3) Collaborative linkage

It establishes cross-department, cross-level, cross-territory, and multi-level collaborative linkage, unifies and coordinates personnel, organizations, resources and facilities, and finally eliminates safety hazards.

(4) Decision-making support

Combining with the urban big data, thematic analysis applications in different professional fields centered themes such as party smart construction, government smart services and business environment etc. can be established. Then deeply dig into the knowledge in the change of urban operation state and provide reference, like data analysis and simulation prediction for making decision. It can be foreseen that via continuous experience accumulation and knowledge precipitation, the CIM platform prediction ability, accuracy of data analysis and decision-making models will be progressively improved.

(5) Command and dispatch

The CIM platform can integrate video monitoring, video conferencing and emergency response systems to provide support for major event protection and emergency command and dispatch. On the basis of audio and video mobilization, it can effectively use various existing network resources, information resources, application system resources to further converge business data of various departments, video monitoring data, etc. By doing so, the CIM platform can realize linkage command of major events. and the command and dispatch of multiple departments' collaborative response, including meteorology, environmental protection, traffic, public security, urban management, health, quality supervision, industry and commerce, forestry, marine fishery, water, electricity, gas, industrial production and other linkage sections, Provided that any type of emergencies happens, the CIM platform is able to command and dispatch based on electronic maps, retrieve the real-time situation on site through video surveillance, and conduct consultation and research with various departments and districts through video conferencing for rapid and effective address of emergencies.

\section{Application Dimenson of CIM}

As a pillar of digital twin city, CIM becomes the premise and key to upgrade from smart city to digital twin city. At the time being, software or its similar for simulation of the entire city have been available yet, for the application scope of simulation software is still confined to detailed segments, to name a few typical examples, SUMO, VISSIM and Carsim for traffic simulation, SITES for landscape environment simulation and Anylogic for logistics/supply chain simulation. With respect to urban planning, conjoining with the hypothesis analysis and virtual planning of CIM simulation, the promote targeted urban planning can be completed appositely and beforehand. 


\subsection{Pre-urban planning - visualization of the status quo, scientific generation of planning}

Obtaining in-depth understanding of urban characteristics and assessing planning impacts at the early stage of planning and construction can help avoid wasting time on infeasible planning or design and prevent any potential redesign at the validation stage. Such efforts can promote, with less cost and faster speed, the implementation of various planning solutions underpinned by innovative technologies. In the pre-urban planning stage, CIM-based integration of data on city history, status quo, and resources can map out the current situation of the city and arrange in advance. At the same time, through hypothesis analysis and simulation projection, such application at the initial stage can promote the top-level urban design to the ground with less cost and faster speed, scientifically assess the planning impact and avoid unviable planning or design.

\subsection{Urban planning stage - urban planning simulation to form optimal global decisions}

Over the urban planning stage, through the simulation of planning schemes and urban design schemes on the CIM platform, trial and error may be conducted in the virtual world, whereas execution may be landed in the actual world. In other words, impacts of planning schemes on the city is dynamically evaluated through thematic analysis and simulation in order to ensure that the comprehensive benefits are optimized when planning every inch of land such as buildings, green spaces, roads, bridges, public facilities, etc. In specific terms, CIM can be used as the foundation to fully incorporate the planning data of urban blueprint, detailed control plan, special plans (such as on land, ecological and environmental protection, municipal special plans, traffic and road networks, industrial economy, etc.) and urban red line, etc., and achieve overlay and integration in digital space. And thereby, it can solve any potential conflicts and inconsistencies of manifold plans and establish a "one city blueprint" with multiple plans taken into account, and moreover, it can be constantly update as the development of the city. Simultaneously, combining with the CIM platform, various planning schemes can be spatially calculated, simulated, projected, and visualized in an clear way to effectively realize the optimization of planning schemes, reduce the cost of urban trial and error, thus truly realizing scientific planning.

\subsection{Urban construction phase - detailed monitoring of projects and building a multi-}

\section{dimensional management perspective}

Urban construction projects are featured as large scale, high complexity, long cycle and wide scope, which render project management rather difficult to scientifically control the schedule, cost, quality and safety of the entire project. By using CIM platform, not only the complex and diverse construction environment be truly restored with all elements for the convenience of interactive design and construction simulation, but it can endow each brick of the city with due attributes of data, for the purpose of ensuring the information exchange of information model in different stages of the whole life cycle of urban construction.

\section{(1) Design stage}

In the design stage of urban construction projects, CIM technology can be used to restore the surrounding environment of the construction project. The advantages of such operation resides in that it makes the interactive design visualized on the one hand, and fully considers the mutual influence factors between the design scheme and the existing environment on the other hand, so that defects that can only be found in the construction stage can be exposed in the virtual design process in advance, which is rather convenient for the designing engineers to optimize these defects in time, and providing reference for construction volume. 
While in the urban survey and design stage, CIM platform can make multi-party collaborative review of urban design plans and integrated collaborative design possible, in order to improve quality and efficiency. Besides, CIM platform also has the capabilities to conduct numerical simulation, spatial analysis, functional simulation optimization and visualization expression, build engineering survey information database, by doing so the platform can finally achieve effective forwarding and sharing of engineering survey information.

\section{(2) Construction stage}

In the construction stage, the temporal and spatial characteristics of subjects in CIM technology can be used to simulate the construction scheme and plan, analyze the rationality of the progress plan, so that it can conduct comprehensive control over the construction process.

In the urban construction stage, on the strength of $\mathrm{CIM}$, the whole process of engineering projects from drawing, construction to completion delivery can all be supervised, while the progress, capital, quality, safety, green construction, raw materials, labor and collaboration of major projects can be supervised in the digital manner. All these operations can realize dynamic, integrated and visualized construction management and ensure on-time, high-quality and safe delivery of major engineering projects, rendering each completed building, infrastructure and other construction subjects include two major achievements of physical entity and digital assets etc. traceable, locatable and analyzable in terms of their quality of engineering construction, delivery and supervision in real time. In summary, the CIM platform can be conducive to realizing real-time communication and multi-party collaboration of each construction party, pre-comparison of models and multiple iterations of entities for construction results, and thus, ensuring quality improvement and cost reduction, green and low-carbon of urban construction and guarantee safety.

\subsection{City O\&G phase - all data retention to support full lifecycle applications}

When the project construction is completed and commences to operation and maintenance, its design and construction data should be fully retained and synchronized with the synchronously built City Information Model (CIM) to build a spatial-temporal database, which can present the details of the completed object in real time and realize remote control and maintenance based on virtual control reality technology.

Following the completion of the architecture project, all the data including the design, construction and assembly process should be retained for the convenience of generating a complete 3D model of the building. By deploying various sensors and monitoring device in the internal and external spaces of the building, all types of data including environment data, equipment operation data, component pressure and strain data, video monitoring data, abnormal alarm data, etc. will be collected and intelligently analyzed to predict and warn in advance the possible building life, equipment health and other problems. In the case where there are potential problems and fault alarms, managing personnel can use VR/AR devices to control intelligent inspection robots for inspection and maintenance, on the basis of which the personnel can diagnose and solve actual problems in physical buildings in the CIM platform. In an effort to cope with disaster prevention and mitigation or emergency response such as earthquakes, floods, typhoons, fires, combustion and explosions, hazardous material leaks, etc., government management department can use the CIM platform and the embedded BIM models to carry out emergency plan simulation, emergency rescue simulation, disaster damage assessment, personnel evacuation and shelter placement guidance, post-disaster recovery planning and other assisted operations etc., so that it can discover experience and laws in the simulation in the digital twin world. At one and the same time, CIM platform can also assist in reducing the cost of trial and error in the physical world and strengthening the positive interaction between "real and virtual". 
Regarding the city operation and management stage, by virtue of CIM integration of IOT perception data, derived from a city's intelligent facilities, it can realize real-time monitoring of urban traffic, energy, ecological environment, urban management and other areas of the city's operating conditions. Through the digital model of various fields of expertise, intelligent algorithms, the city has the capabilities of achieving rapid response, decision-making simulation, emergency disposal and intelligent control, which will improve the level of urban operation and management and emergency disposal capacity, entailing a more safe and reliable city.

Finally, as for the evaluation of the benefits of smart city projects, CIM platform can be conducive to build a model and analyze urban traffic conditions, human flow gathering distribution, air quality, water quality indicators and other dimensions of urban data, according to the results, decision makers and evaluators can quickly and straightforwardly understand the effect of smart city and its environment, urban operation and other improvements, evaluate the benefits of the construction of smart projects, urban data mining analysis, and thus in the long term, it can assist the scientific decision-making for government in the information technology and "smart" construction, to avoid detours or repeated construction of low-benefit construction.

\section{Application scenarios of CIM}

\subsection{CIM+Urban Renewal}

On the CIM platform, the urban renewal projects are investigated and analyzed by "four standards and four actualities" as the main contents of the special urban governance campaign, namely, standard operation drawing, standard building code, standard address database, standard basic grid, actual population, actual housing, actual units, and actual facilities. Within the framework, the population, units and housing will be analyzed and renewed (Fig.5).

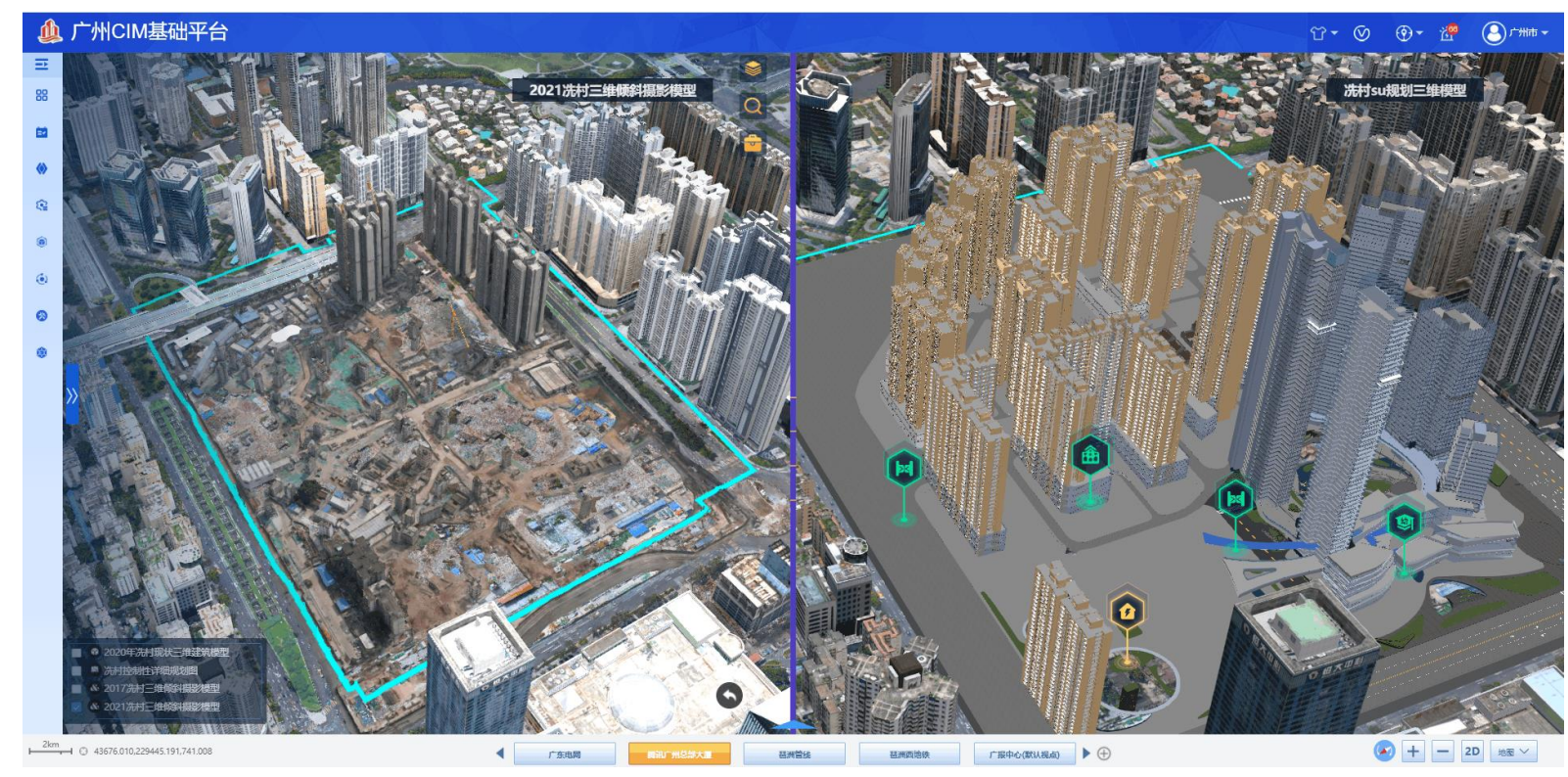

Figure 5. The application interface of urban renewal. Source: Augur Intelligence Technology (Guangzhou) Co., Ltd

In this application scenario, compare the effect before and after the renewal via the presentation of dual screens; showcase the detailed planning scheme by combining with the 3D planning model, and analyze the surrounding site and real estate market situation on the basis of surrounding supporting facilities. The main applications include: 
(1) This application can realize the data sharing of 183 urban village transformation projects available with the help of CIM. It has distinguished the three-year plan and five-year program in the system with different colors. At the same time, the data of "three old transformation" in Guangzhou and the distribution of old neighborhood transformation projects are also available in the system for statistical presentation (Fig.6).

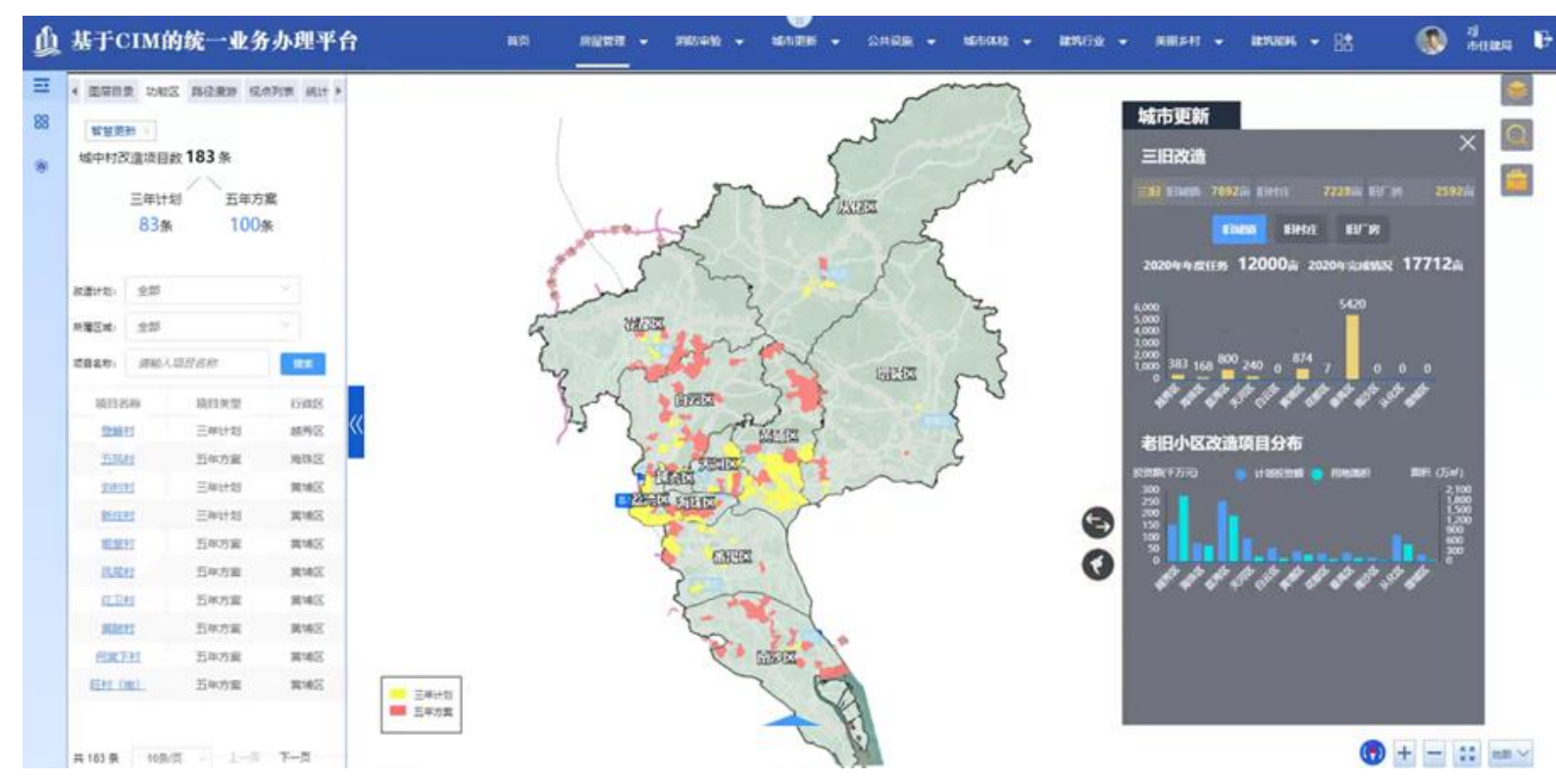

Figure 6. Guangzhou "three old transformation" and the distribution of old district transformation projects. Source: Augur Intelligence Technology (Guangzhou) Co., Ltd

(2) Taking the renovation project as per unit, the renovation scope of the project is highlighted and showcased in the CIM map, so as to calculate the basic status quo data, including population, economy, building area, etc.; at the same time, conjoining the data of "four standards and four actualities", the information of the actual population, actual housing and actual units can be analyzed; the system can also estimate building area, i.e. estimating the status quo of the scope as per the scope of the project, providing reference data for the basic data of urban renewal projects (Fig.7).

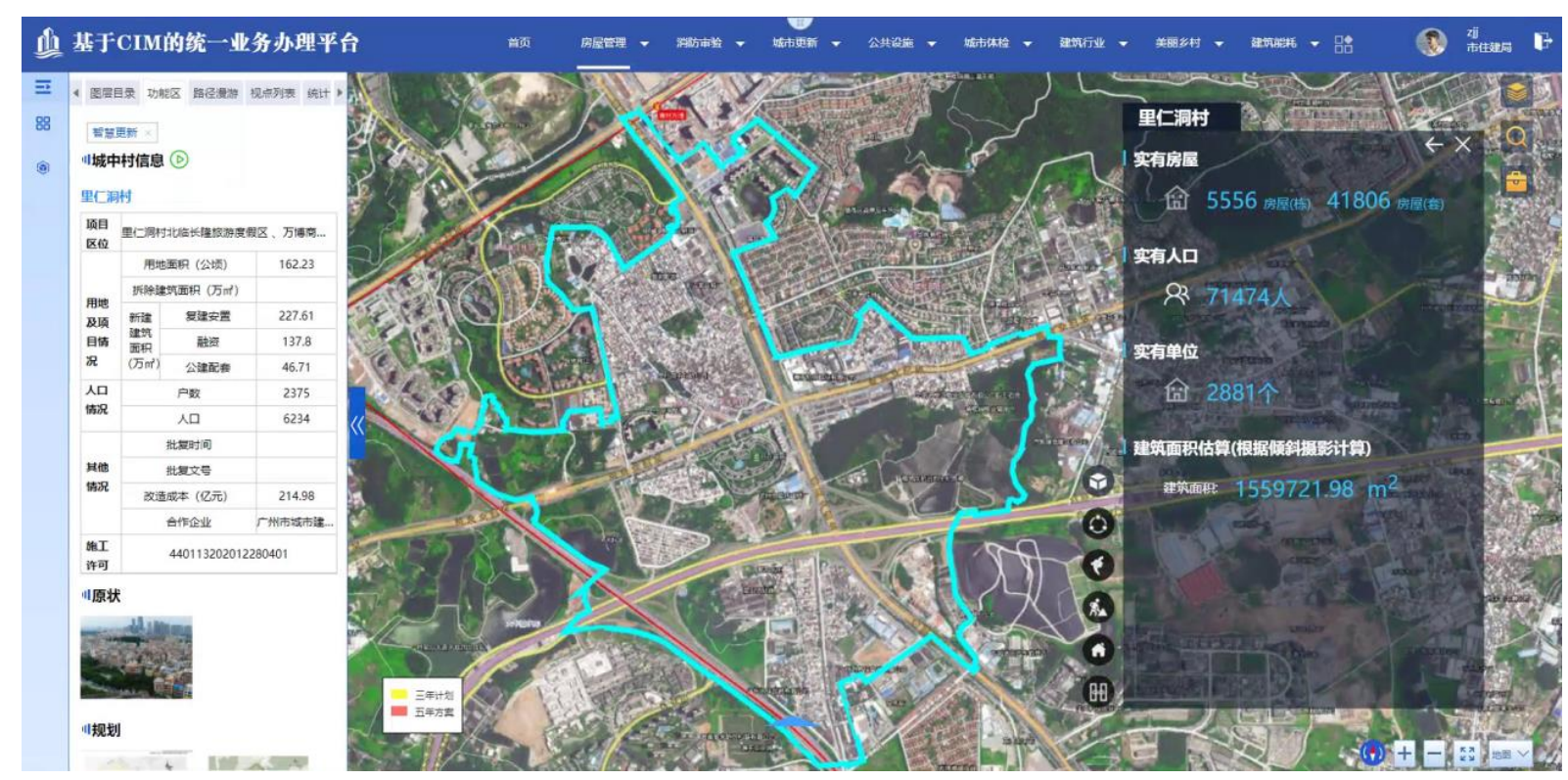


Figure 7. Actual population/house/unit statistics. Source: Augur Intelligence Technology (Guangzhou) Co., Ltd

(3) Aligning the progress and investment information of the project. In this application scenario, it can carry out intelligent supervision on the scope of the renovation project in the construction phase, showcasing and monitoring the whole progress and investment information of the project (Fig.8).

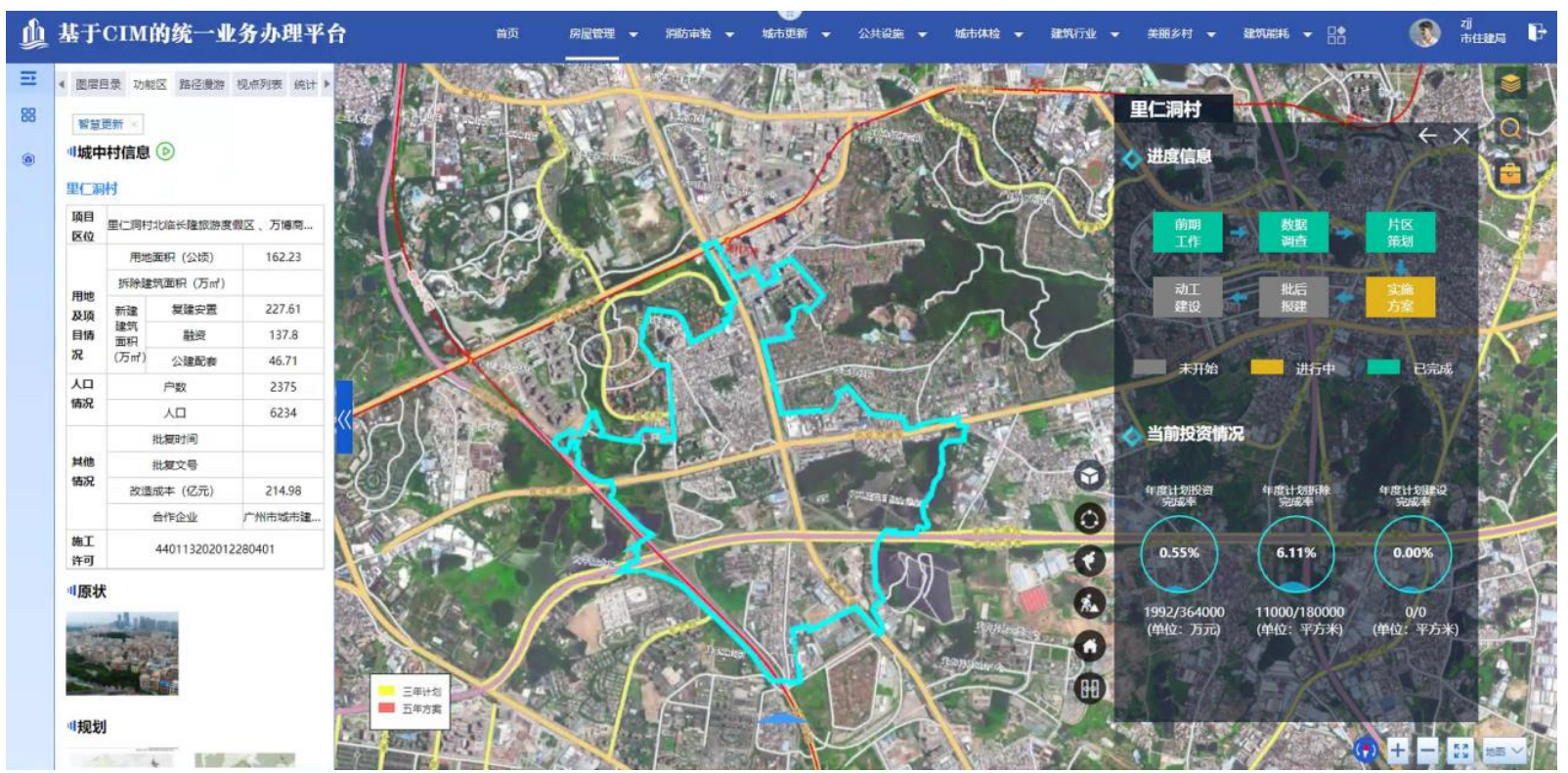

Figure 8. Project progress, investment monitoring. Source: Augur Intelligence Technology (Guangzhou) Co., Ltd

(4) On the basis of the on-site intelligent supervision system, such application can analyze the distribution of construction sites within the transformation area, and align the supervision system to learn the site situation in real time (Fig.9).

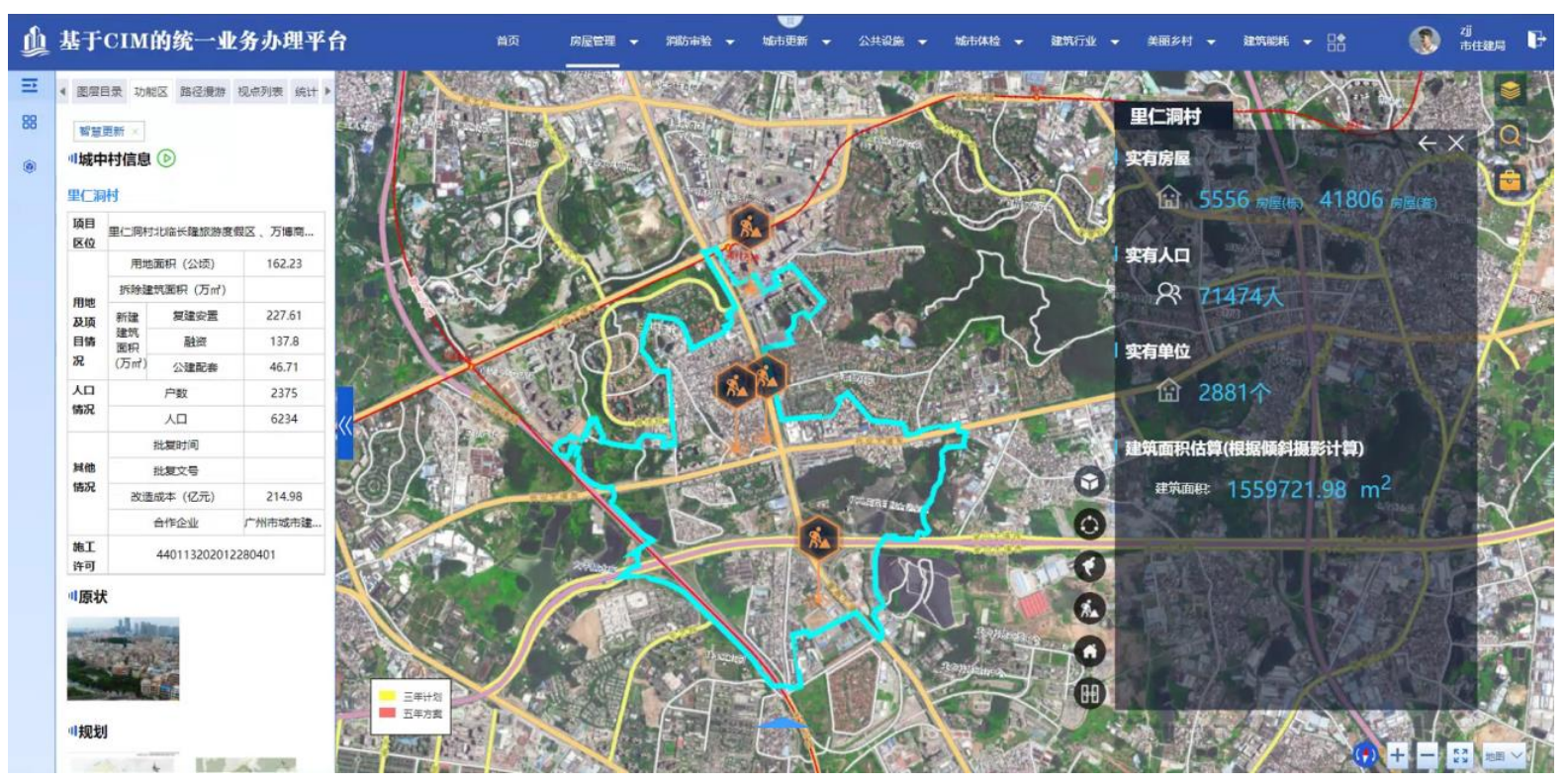

Figure 9. Smart site supervision system. Source: Augur Intelligence Technology (Guangzhou) Co., Ltd 
(5) The application is able to analyze the dynamic changes of the real estate market within and without the transformation area in conjunction with the property projects (Fig.10).

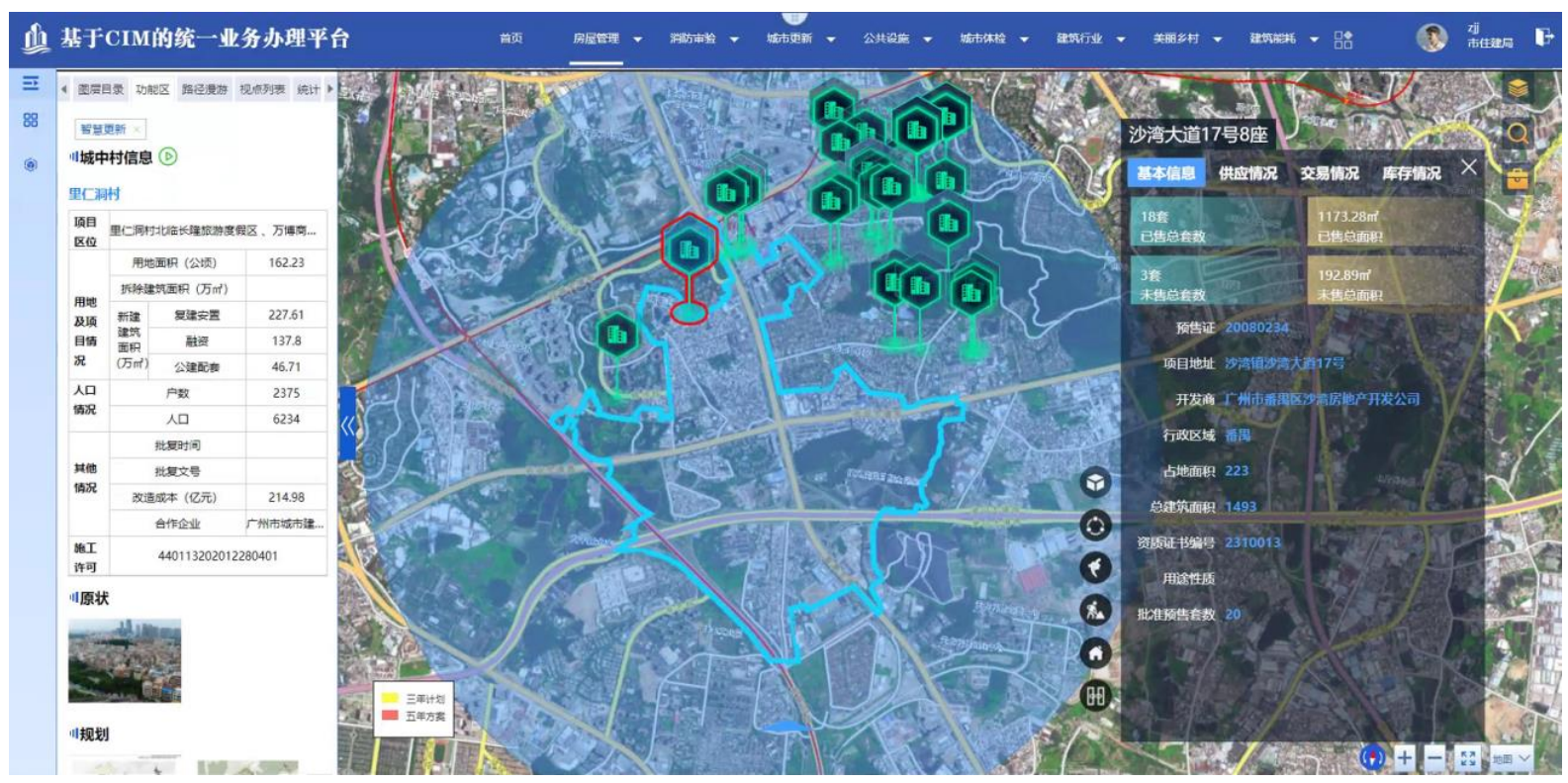

Figure 10. Property and transaction. Source: Augur Intelligence Technology (Guangzhou) Co., Ltd

(6) Such application can align the record on the process of transformation project, through the method of atlas, the information such as original state, planning, implementation progress, effect map, etc., can be demonstrated straightforwardly (Fig.11).

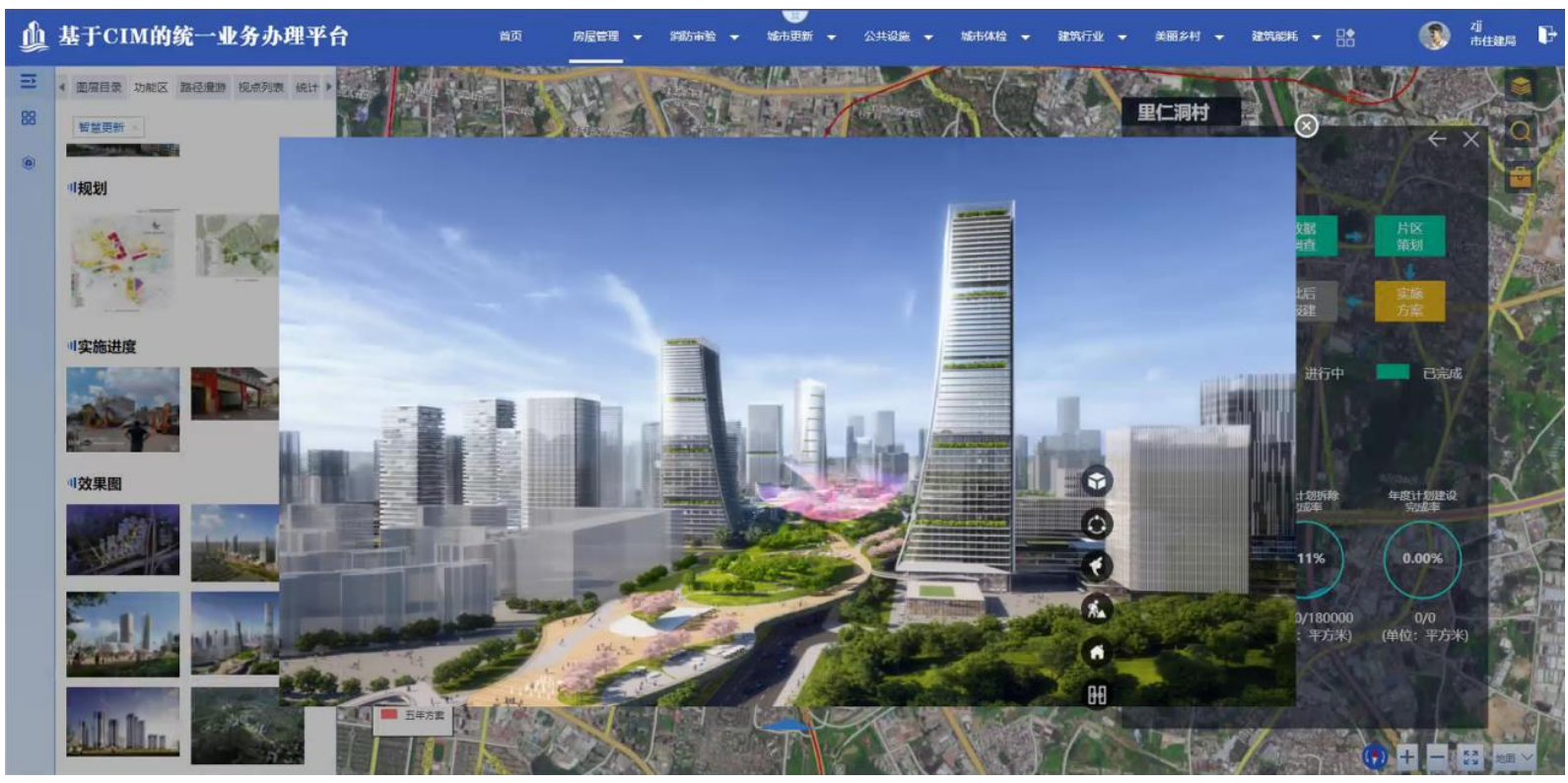

Figure 11. Effect drawing of the renovation project. Source: Augur Intelligence Technology (Guangzhou) Co., Ltd

(7) Through the dual-screen display, a comparison on the effect before and after the transformation can be showcased. In this diagram, the left column is the transformation status quo, which can be displayed by tilting photography model over the years, whereas the right column is the effect after the transformation, shown by the project planning model (Fig.12). 


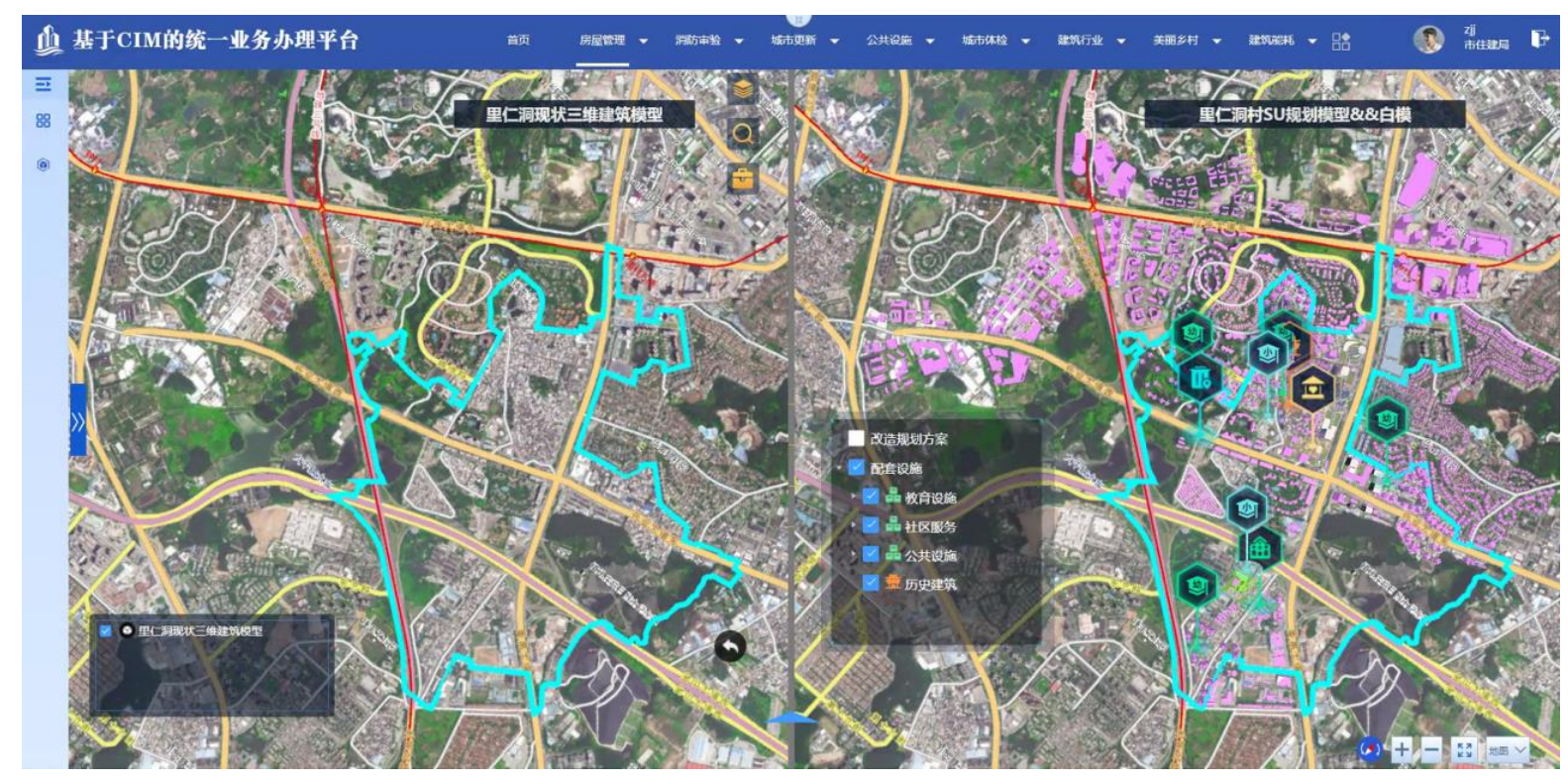

Figure 12. Comparison of before and after renovation. Source: Augur Intelligence Technology (Guangzhou) Co., Ltd

(8) In this process, 3D planning model may be adopted to showcase the detailed surrounding facilities, including kindergartens, substations and other public facilities and detailed planning schemes (Fig.13).

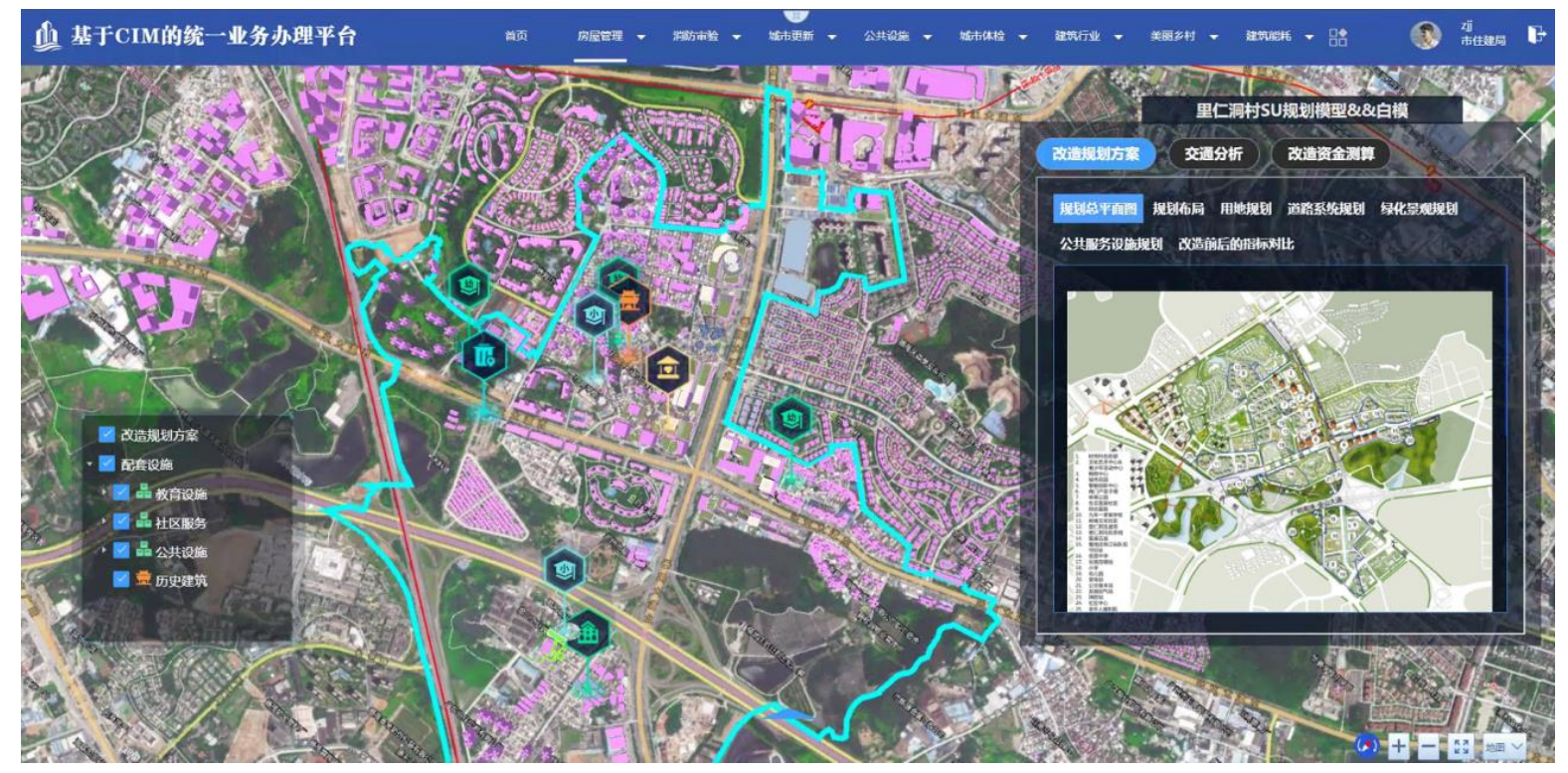

Figure 13. Three-dimensional planning model display. Source: Augur Intelligence Technology (Guangzhou) Co., Ltd

\section{2. $\mathrm{CIM}+$ vehicle-road collaboration}

In an effort to study the application of CIM platform in vehicle-road collaboration, 9 blocks in 5 districts, including Tianhe District, Huangpu District, Huadu District, Panyu District and Nansha District were selected as pilot projects, it turned out that the efforts have achieved good results in terms of intelligent transformation of facilities, actual road testing, intelligent travel demonstration and exploration of common construction and sharing. At present, CIM platform is focused on aligning with the pilot project of "Guangzhou artificial intelligence and digital economy experimental zone Pazhou area" to further explore in this domain. Via accessing to the data of CIM HD simulation of three-dimensional scenes of 
Pazhou pilot area and road test data of the city network, it can simulate the driving environment and establish a virtual driving cab to support the intelligent management of the city network(Fig.14). In the meantime, the specific application of CIM base platform and vehicle-city network integration in the application scenarios, including the self-driving shuttle, unmanned logistics, self-driving sanitation, region-wide parking information service, vehicle-road cooperation service, vehicle-city integration management, vehicle-road cooperation traffic signal optimization, etc. can all be examined.

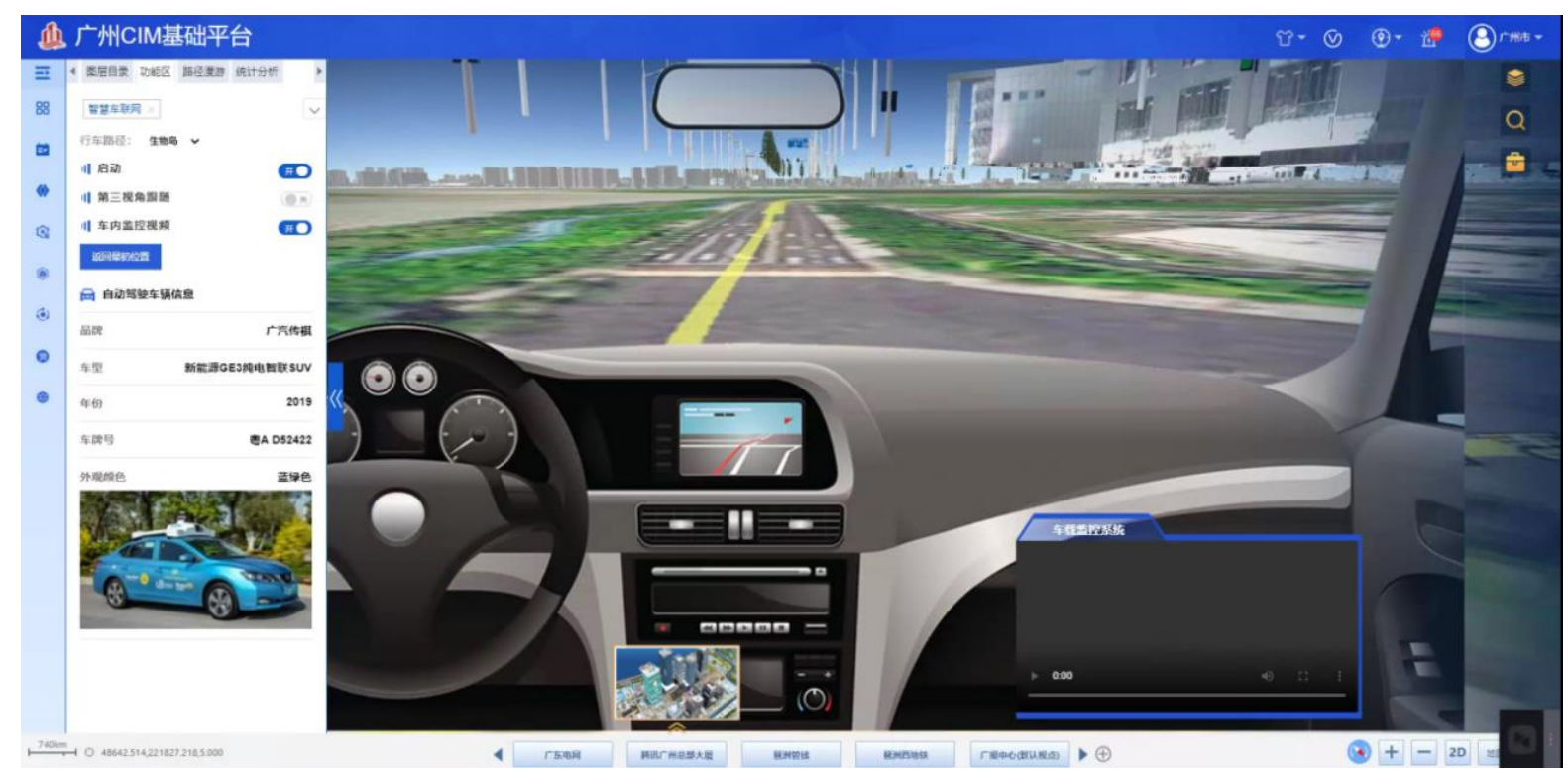

Figure 14. Self-driving simulation. Source: Augur Intelligence Technology (Guangzhou) Co., Ltd

\section{3. $\mathrm{CIM}+$ Housing safety management}

Two-three-dimensional intelligent housing management system on the basis of CIM platform can be established to realize the visualization of housing management. The system can access the data from the automatic dynamic monitoring of housing in real time so that the monitoring and early warning of housing safety can be available, and a complete closed loop of "finding-filing-dispatching-processingverifying-closing" can be realized. It is self-evident that such operation is able to realize the detailed and intelligent management of housing safety. Specifically speaking, with the precise perception and artificial intelligence technology, the intelligent housing management system on the basis of CIM platform can connect with monitoring equipment such as level meter, inclinometer, crack meter, etc. to conduct whole-life safety diagnosis and safety monitoring in a real-time manner. This is how the management system ensures the safety of houses in the event of strong winds, earthquakes, and human interference (such as pit construction), etc. Besides, it can conduct comparative analysis of theoretical values to the real-time dynamic monitoring and evaluation of houses, based on which, it can give real-time early warning forecast to improve the level of intelligent control. The management system should conjoin with the city's housing census information to demonstrate the housing census results in the CIM map overlay, and form a statistical analysis of various indicators such as area and safety level(Fig.15). 


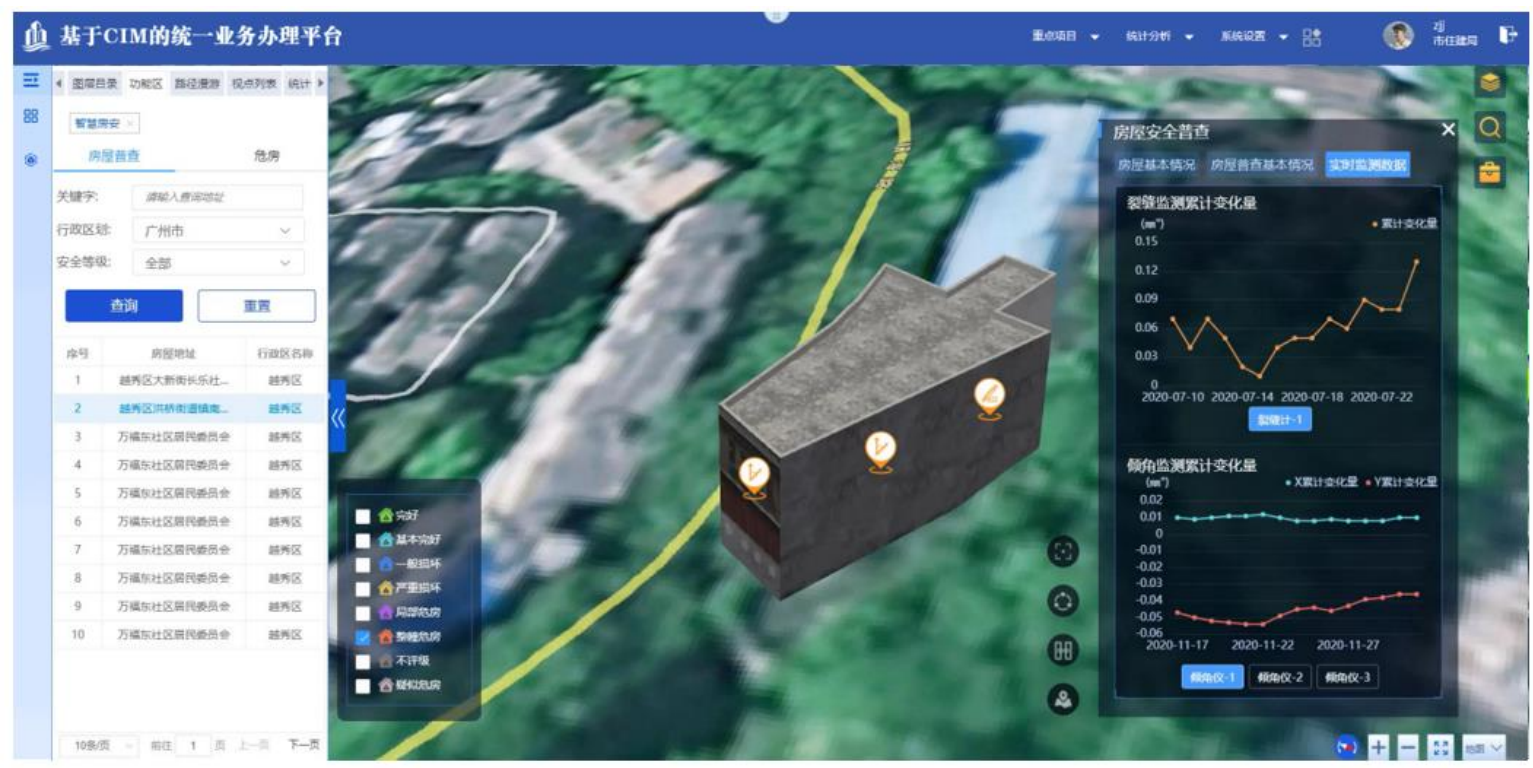

Figure 15. The application of intelligent housing safety management. Source: Augur Intelligence Technology (Guangzhou) Co., Ltd

(1) The housing safety information can be incorporated in the CIM map. The housing safety level is shown as per different colors, i.e. the red column indicates dangerous houses, while the green column stands for safe houses. In this way, the safety degree can be learned in a straightforward manner(Fig.16).

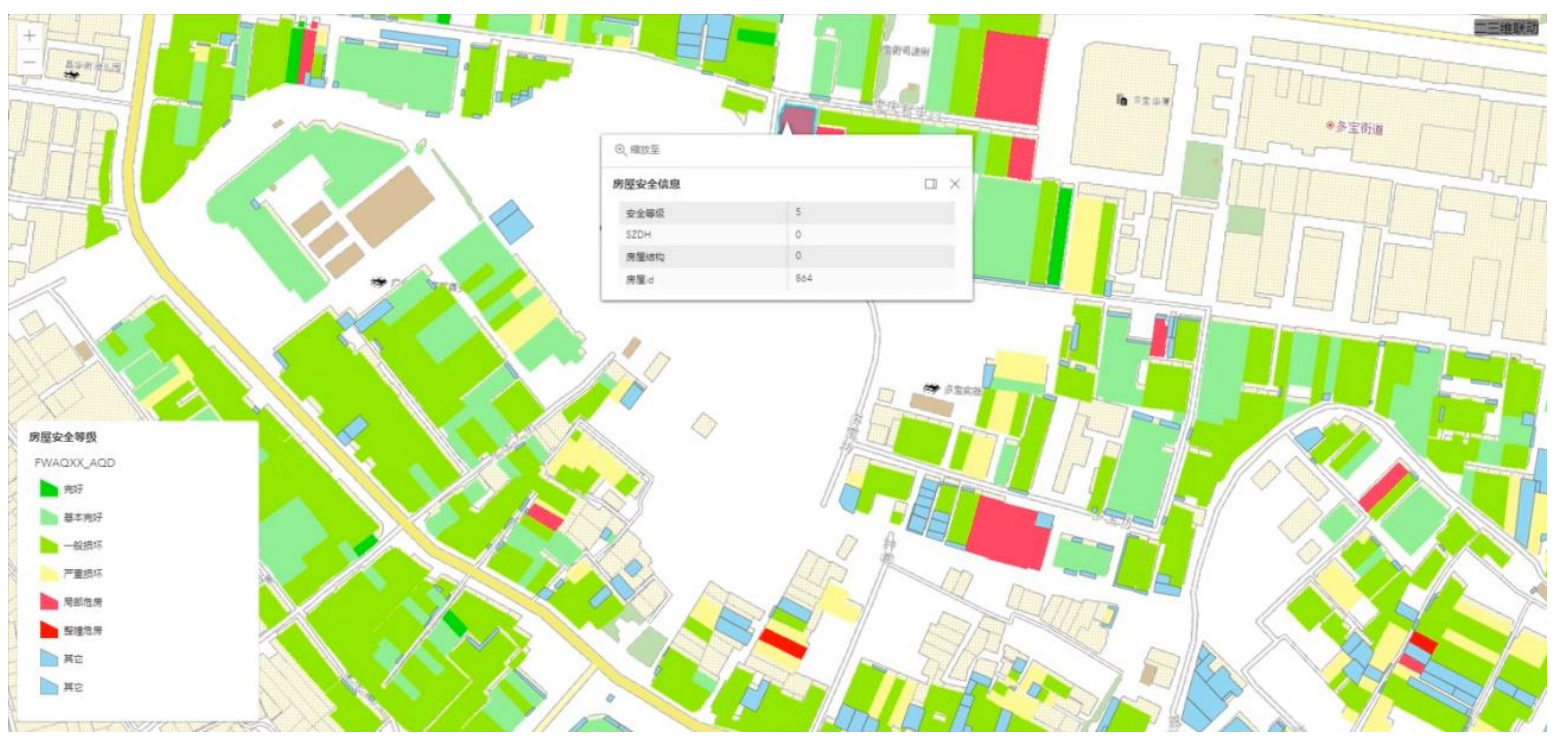

Figure 16. Housing safety information display. Source: Augur Intelligence Technology (Guangzhou) Co., Ltd

(2) With the help of 2D and 3D connection in terms of housing of CIM foundation platform, the location of housing can be precisely identified, while the status quo of housing can clearly and precisely shown. This is how to realize housing safety supervision of all aspects(Fig.17). 


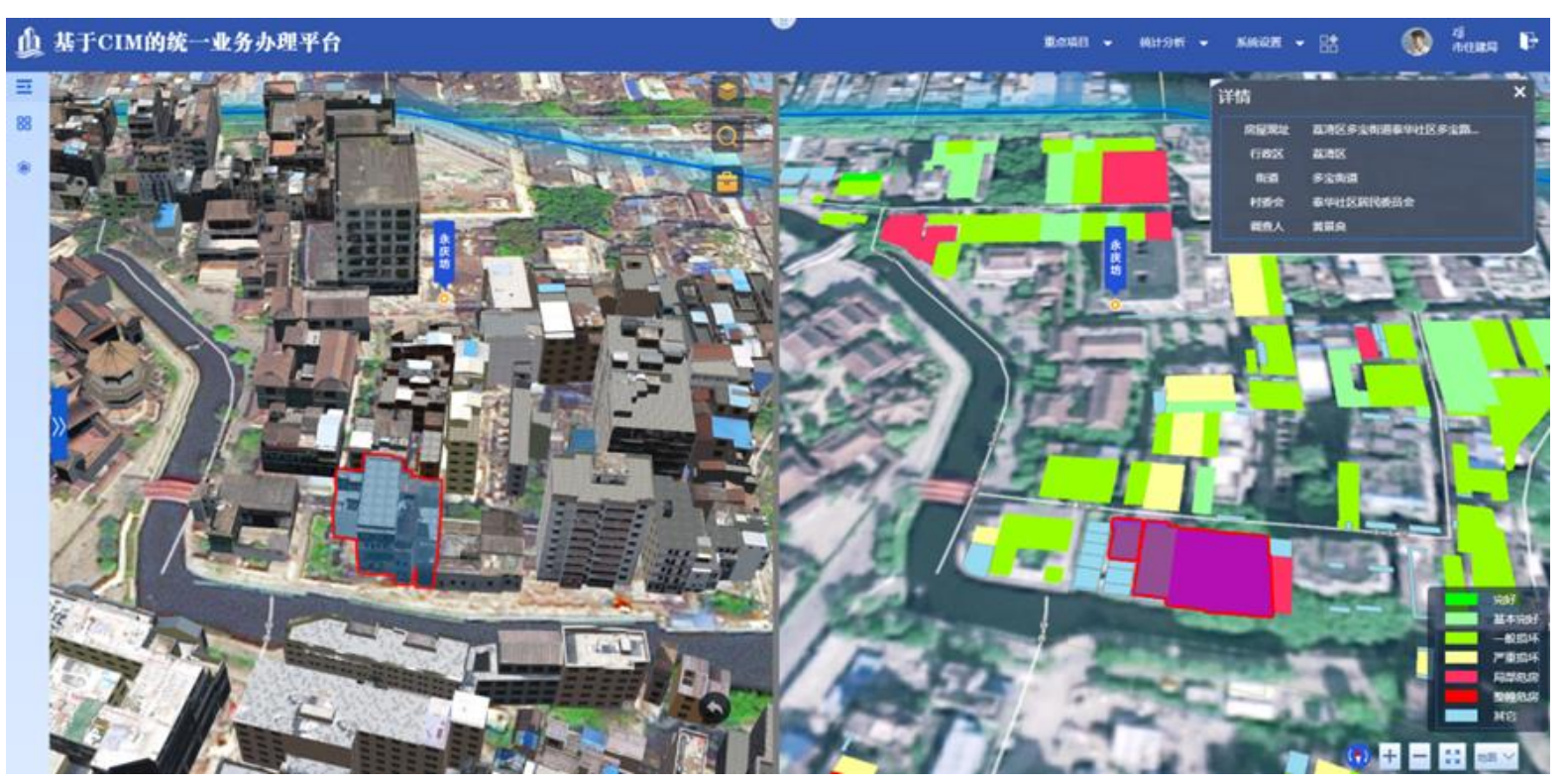

Figure 17. Housing 2D and 3D connection display. Source: Augur Intelligence Technology (Guangzhou) Co., Ltd

\section{Summary and Prospect}

The construction of CIM platform can promote the application of BIM technology in the whole process of engineering and construction projects, making computer-aided approval come true and minimizing manual intervention to the least. What's more, it also improves quality and speed for project approval, and promotes business environment and innovation environment. Meanwhile, the construction of CIM platform also enhances the in-depth application of data resource, providing simulation of multi-scale and analysis on planning and construction management. It also contributes to deepening staff's understanding of the urban construction and optimizing the scientific nature of data resource-assisted decision-making.

In the time to come, Guangzhou City will further expand and improve the existing data system and standard system by increasing the data collection work, so that it can consolidate and solidify the data foundation of CIM platform. On the basis of the existing accumulation, the CIM platform should be further improved in term of its digital expression of all elements, visualization presentation, data fusion supply, spatial modelling and analysis calculation, simulation deduction, computer-aided review of the whole life cycle of engineering construction projects, virtual-real integration interaction, IOT perception control etc.. It should also pay special attention on promoting $\mathrm{CIM}+$ wisdom applications, accelerating the development of urban governance and application innovation in various sectors, including housing and construction of urban and rural, water, transportation, emergency management, fire fighting, urban management, industrial informatization, environmental protection, public safety, education, forestry and gardening, public health, culture and tourism, as well as business etc. What's more, it should be able to provide momentum to the application of independent and controllable technology and the development of related industries, to progressively realize the interconnection among mega-city CIM platform, national and provincial CIM platforms in an effort to build a unified and hierarchical platform according to administrative regions and management liabilities. Such campaigns will comprehensively promote the level of scientific, refined and intelligent governance of Guangzhou City.

At one and the same time, the opportunity of "constructing new urban" should be made full use. Through relevant projects, effective investment may be boosted, new economic growth points developed, and 
new momentum of development established. The CIM, as an open-source platform, can provide data interfaces to government, enterprises and academia after authorization, thereby becoming "land supply" for city-level application, rendering the CIM data entailing more social and economic value.

\section{References}

[1] Xu X, Ding L, Luo H,et al. (2014) From Building Information Modelling to City Information Modelling [J]. Journal of Information Technology in Construction, 19: p292-307.

[2] Wang B ,Tian Y . (2021) Research on Key Technologies of City Information Modelling [J]. IOP Conference Series: Earth and Environmental Science, 693(1),p1-2.

[3] Li Luying. (2014) Construction of New Smart City Platform Based on City Information Model (CIM)Taking Guangzhou as an Example [J]. Smart city, 7 (03), p35-36

[4] Shi Xiao, Zhong Lin, Liu Xian. (2020) Application of City Information Model (CIM) platform in Urban Renewal and Reconstruction of Guangzhou-Taking the Renewal and Reconstruction of Jinzhou and Chongwei Natural Village as an Example [J]. Urban Architecture, (23), P9-12 